Title:

Disentangling the correlated evolution of monogamy and cooperation

\author{
Authors: \\ Jacqueline R. Dillard ${ }^{1}$ and David F. Westneat ${ }^{1}$ \\ ${ }^{1}$ University of Kentucky, Department of Biology and Center for Ecology, Evolution, and \\ Behavior, 101 Thomas Hunt Morgan Building, Lexington, KY 40506
}

Corresponding author: Dillard, J. R. (jacqueline.dillard@uky.edu)

Keywords: Hamilton's rule, relatedness, cooperative breeding, helping, mating system, coevolution

(C) 2016. This manuscript version is made available under the Elsevier user license http://www.elsevier.com/open-access/userlicense/1.0/ 


\begin{abstract}
Lifetime genetic monogamy, by increasing sibling relatedness, has been proposed as an important causal factor in the evolution of altruism. Monogamy, however, could influence the subsequent evolution of cooperation in other ways. We present several alternative, nonmutually exclusive, evolutionary processes that could explain the correlated evolution of monogamy and cooperation. Our analysis of these possibilities reveals that many ecological or social factors can affect all three variables of Hamilton's Rule simultaneously, thus calling for a more holistic, systems-level approach to studying the evolution of social traits. This perspective reveals novel dimensions to coevolutionary relationships and provides solutions for assigning causality in complex cases of correlated social trait evolution, such as the sequential evolution of monogamy and cooperation.
\end{abstract}




\section{Monogamy and the evolution of cooperation}

Lifetime monogamy has recently been invoked as a critical causal factor in the evolution and maintenance of cooperation in family-based social systems where helpers are offspring of the breeding individual or pair [1,2]. Lifetime genetic monogamy ensures that relatedness between helpers and the siblings they help rear is at least as high as the relatedness between helpers and their own offspring $\left(r_{\text {sibling }}=r_{\text {offspring }}=0.5\right)$. When the relatedness between the altruistic actor and the offspring of the recipient is equivalent to the relatedness between the actor and its own offspring, the relatedness terms in Hamilton's Rule $\left(r_{\text {sibling }} b>r_{\text {offspring }} c\right)$ cancel out. Altruistic helping can then be favored when the benefits only marginally exceed the costs $(b>c)[1,3]$. Without genetic monogamy, $r_{\text {sibling }}<r_{\text {offspring }}$, and benefits must greatly exceed costs for cooperation to spread. Monogamy has thus been argued to provide a "window" through which social organisms must pass before the evolution of sterile worker castes can occur $[1,2]$. Though this logic was initially used to explain the evolution of worker sterility in eusocial systems $[1,4]$, genetic monogamy could also be an important factor in the evolution and maintenance of less permanent forms of cooperation such as cooperative breeding in familybased societies $[5,6]$.

Correlations between monogamy and cooperation have been observed in several taxonomic groups. The evolution of sterile worker castes in eusocial hymenoptera is restricted to those lineages with ancestral lifetime monogamy, and polyandry appears to arise only after the loss of worker totipotency [4]. In birds, cooperative breeding appears more often in lineages with low promiscuity [5]. In addition, within cooperative bird species, helping frequency and promiscuity are negatively correlated [5]. In mammals, family-based cooperative breeding societies have also arisen only in socially monogamous lineages [7] (but see [8]). Furthermore, extra-pair paternity in socially monogamous mammals is rare and social bonds between males and females tend to be long lasting [7]. This results in genetic monogamy that could persist for several breeding cycles, allowing the opportunity for offspring helpers to assist in rearing full 
siblings $[7,9]$. Likewise, in birds extra-pair paternity and divorce rate are positively correlated, implying similarly long lasting periods of high sibling relatedness in genetically monogamous species [10].

The idea of genetic monogamy being an important prerequisite for the evolution of offspring helpers is both intuitively appealing and seemingly well supported in comparative analyses. However, genetic monogamy and cooperative breeding are both attributable to an array of ecological and social factors and are characterized by complex coevolutionary dynamics. Comparative studies that support the monogamy hypothesis have considered only a single link between monogamy and cooperation through sibling relatedness, and have thus ignored alternative explanations for this evolutionary correlation. Owing to the complex relationship between mating behavior and social behavior, a perspective that integrates the interactions that characterize these dynamic systems is necessary for evaluating the relationship between monogamy and cooperation. We adopt this perspective and use it to outline three alternative evolutionary processes that could account for the disproportionately high occurrence of cooperation in monogamous lineages (Fig. 1). We present these alternative pathways not to question the role of relatedness in the evolution of cooperation, but rather to highlight the potential complications faced when assessing causality in complex evolutionary relationships. By recognizing the codependence of mating systems and social systems in this way, we further demonstrate that some evolutionary or ecological factors could influence multiple terms in Hamilton's Rule simultaneously. This suggests that certain factors might lead to correlated changes to both relatedness terms and the benefits/cost ratio to synergistically favor helping. This finding has implications for both the correlated evolution of monogamy and cooperation as well as the more general framework of social evolution.

Ecologically Driven Covariance: The same ecological selective pressure favors two traits simultaneously. 
Before assigning a causal relationship between two traits, it is important to demonstrate that the trait correlation is not caused by additional confounding variables. For instance, if a common selective pressure influences both traits similarly, the covariance between these traits could be consequential rather than causal. This is likely to be important in the example of monogamy and cooperation. Both theoretical treatments (Box 1) and a brief review of the ecological factors predicted to favor monogamy and cooperation reveal that similar selective pressures are likely to influence both traits (summarized in Table 1). Due to tradeoffs between mating effort and parental effort, genetic monogamy is generally favored when the value of providing parental care is high and mating opportunities are low [11-18]. A similar tradeoff exists for helpers, and helping effort is favored over independent breeding effort when the value of additional care is high, or when the likelihood of successfully breeding independently is low (Fig. 1b) [3,19-21]. When mating or breeding opportunities are limited, the benefits of either mate desertion or offspring dispersal are reduced, and both mate fidelity and delayed dispersal with helping can be favored even when the payoffs are relatively low. Parenting and helping can thus be thought of as similar phenomena, shaped by similar selective pressures that increase the benefits of care or reduce the benefits of deserting or dispersing. While the conceptual similarities between monogamy and cooperation have been mentioned elsewhere [22,23], the implications of these similarities for the correlated evolution of monogamy and cooperation have not been thoroughly addressed.

This process could also account for the observed evolutionary sequence of monogamy preceding cooperation if, for instance, factors favoring both cooperation and monogamy undergo a directional change through evolutionary time, passing first through values where biparental care but not cooperation is favored before reaching values where both are favored (Fig. 2a). Reductions in food abundance, for example, could initially select for the combined provisioning effort of both parents, leading first to social and possibly genetic monogamy through selection favoring biparental care. If food resources progressively deteriorate or 
become more difficult to obtain over evolutionary time, families that retain adult offspring helpers could be better able to deal with this increasing environmental harshness. The sequential evolution of cooperation between partners and cooperation between additional family members could therefore allow lineages to track increasingly more difficult foraging niches. In carnivores, for example, larger prey is more easily obtained and defended in groups [24-27]. A transition to larger prey, either through a shift in foraging niche or coevolution between predator and prey, would then favor increased group size from singleton to pair or from pair to pack depending on prey size and abundance. Group size in coyotes, for example, fluctuates seasonally, increasing as the abundance of large prey species such as deer and elk increases [24]. Importantly, pairs of coyotes capture and defend large carcasses better than singletons, and this benefit increases with pack size [24], suggesting that both pair cooperation and pack cooperation could be favored, at least in part, for the same function.

Phylogenetic facilitation through pre-adaptions: The evolution of one trait increases genetic variation for traits that can be co-opted for other uses.

Certain traits could consistently precede others in evolutionary time if the ancestral trait is easily co-opted for use in subsequent selective environments. In the case of monogamy preceding cooperation, for example, strong social monogamy, which often involves physiological and hormonal adaptations to social living, could have pre-adapted lineages to more advanced social behaviors like cooperative breeding (Fig. 1c). Though social monogamy and genetic monogamy are often decoupled in vertebrate systems, high levels of biparental care and pair coordination are typically correlated with genetic monogamy $[9,28-31]$. Thus, the most genetically monogamous lineages might also be expected to exhibit the highest levels of parental and social coordination between partners, providing pre-adaptations for the subsequent evolution of cooperative breeding. We use "pre-adaptation" simply to describe traits that are easily co-opted or modified for use in contexts different from the ancestral function. Pre- 
adaptations stemming from social monogamy and biparental care therefore do not guarantee the subsequent evolution of cooperative breeding in this view, but rather make the subsequent evolution of cooperation more probable by providing the necessary antecedent phenotypic variation needed for lineages to respond to selection for helping.

The hormonal underpinnings of many social behaviors, for example, are similar for both monogamous and cooperative adaptations, particularly in vertebrates. In mammals, social bonding in monogamous pairs and in cooperative groups appears to be controlled by similar hormonal mechanisms, namely, an increase in the production of the neuropeptides oxytocin and vasopressin and their receptors [32-34]. Biparental care and alloparental care also share strikingly similar hormonal mechanisms, and are both associated with increased levels of prolactin and reduced testosterone in birds [35], mammals [32-34], and fish [36,37]. The onset of paternal care could also prime lineages for the evolution of male helpers, which are common in many avian systems [20]. Ancestral biparental care and social bonding might therefore facilitate cooperative breeding if the shift to cooperation involves merely a change in the timing and context of expression of social and parental traits in the extended family group.

Monogamy also equips lineages with cognitive pre-adaptations to social living. Large brains and high cognitive performance can be important adaptations to living and interacting in complex social situations involving behavioral coordination, negotiation, and division of labor for both pair-bonded couples as well as cooperative family groups [38]. Comparative studies have shown a positive correlation between social monogamy and brain size in birds and mammals, including humans [39-41], that is believed to be in part due to selection arising from biparental cooperation. Brain size also correlates positively with cooperative breeding in mammals [42], though this 'social brain' hypothesis has yet to be supported in birds $[43,44]$. These studies, however, have only examined the relationship between brain size and cooperation in a single avian group (corvids) [44], or have used flock size as a measure of sociality [43], and thus may 
might not have properly assessed whether specific cognitive abilities related to social behavior and cooperation are correlated.

Evolving and co-evolving selective pressures: The evolution of one trait increases selection for a subsequent trait

The evolution of traits, particularly social ones, can change the selective environment for subsequent generations. For example, traits expressed by parents, dependent offspring, and offspring helpers within the family setting represent interacting phenotypes, where both the expression and fitness payoffs of these social traits, such as providing care, depend on interactions between phenotypes in the group [45-47]. The evolution of social monogamy and biparental care could therefore alter the selective environment for helping by influencing both the local social environment (the family) and population demographics in ways favorable to the evolution of cooperative breeding (Fig. 1d) [48,49].

Parental care in general favors adaptations in offspring that make young more efficient at demanding, receiving, and utilizing parental care [45,50]. The advent of these offspring traits in turn changes the selective environment for parents, resulting in parent-offspring coevolution [45]. The addition of male care in biparental systems could have allowed already altricial offspring to become even more dependent on parental care due to the added safety and care afforded by two parents [51]. Increased dependency of offspring could further shape the social selective environment such that the value of care is increased for both parents and helpers, thus increasing the benefits of cooperative brood care. Indeed, phylogenetic analyses have revealed that the evolution of altriciality and cooperative breeding are correlated in evolutionary time, suggesting that offspring dependency might increase the value of care, thus favoring the evolution of cooperation [52].

Similarly, year-round territoriality and joint-territory defense associated with lifetime monogamy influence population demography in ways that both make territory acquisition more 
difficult for young adults and increase the value of cooperative defense [53-56]. It is unclear whether joint defense of a territory is a cause or consequence of lifetime monogamy.

Regardless, the subsequent evolutionary changes to demography (e.g. increased habitat saturation) and difficulty in obtaining breeding territories due to joint-defense are likely to have further shaped the social selective environment. Dispersing juveniles in such systems have poor prospects, and so joint territory defense might favor juveniles that delay dispersal and contribute to defense and brood care. Evidence suggests that year-round territoriality promotes the evolution of cooperative breeding in birds, suggesting that social mating decisions could influence demography in ways that favor cooperation $[48,49,53]$.

Alternatively, the evolution of cooperation could shape the selective environment in ways that favor monogamy (Fig. 1e). For instance, monogamy would be advantageous in a social environment where helpers preferentially help rear only full siblings. Kin recognition and preferential care of close relatives has been observed in a number of taxa [57-59], and the benefits of this help (e.g. enhanced nest productivity) are higher in species with greater levels of kin discrimination [58], suggesting that helpers could select for mate fidelity in parents. Helpers might also increase parent fidelity by actively preventing their parents from re-mating [60]. While this sort of process would not explain the evolutionary transitions from monogamy to cooperation, it is consistent with contemporary correlations between monogamy and cooperation [5] and presents yet another facet of the complex coevolutionary dynamics between cooperation and monogamy.

\section{Implications for Hamilton's Rule}

Investigating these coevolutionary processes reveals that certain factors could influence multiple terms in Hamilton's rule simultaneously in complex ways. Sibling relatedness, for example, is a consequence of mating decisions, and the causes and consequences of these decisions have major influences on both the selective environment as well as the available trait 
variation upon which selection can act. This implies that the terms in Hamilton's Rule are not modular, but are likely to covary, possibly across a wide array of circumstances. While the idea that relatedness is a dynamic, rather than static, variable has been presented in inclusive fitness models of dispersal (Box 2), the full spectrum of circumstances in which this is likely to occur and the consequences of this dynamic covariance for the more general framework of cooperative evolution have yet to be completely explored. Here, we have identified several additional processes that could contribute to this covariance among terms. For example, if the selective environment favors increased care of young, both social monogamy and cooperation should be favored resulting in a simultaneous increase to both sibling relatedness (through selection for monogamy) and the benefits/costs ratio. Here, helping is favored directly by the selective environment through changes to $b$ and $c$ and indirectly through increased sibling relatedness by selection for parent fidelity (Fig. 2b). In addition, from an evolutionary perspective, monogamy influences not only sibling relatedness, but also the social selective environment through parent-offspring coevolution and changes to demography, potentially increasing $b / c$ and sibling relatedness simultaneously. The subsequent evolution of cooperation is also made even more likely if that lineage, by being ancestrally monogamous, possesses social traits that could be co-opted for cooperative behaviors.

\section{Future directions}

Although the many layers of codependence between traits described above complicate the assignment of causal relationships in the correlated evolution of traits, we contend that careful attention to alternative hypotheses and the use of novel comparative techniques could provide a better understanding of these systems. Relatively new advances in phylogenetic confirmatory path analyses provide tractable ways with which to assess causal relationships and their effect sizes in systems where many causal pathways must be examined [61]. This statistical technique uses information theory and model selection to test among multiple 
hypothetical causal pathways while controlling for non-independence due to phylogenetic relationships [61]. These phylogenetic confirmatory path analyses have already been successfully employed to sort out other complex evolutionary questions $[62,63]$, and are likely to prove integral in solving remaining evolutionary problems, such as the correlated evolution of monogamy and cooperation.

Currently, no comparative studies investigating the correlation between monogamy and cooperation have considered alternative hypotheses for this observed pattern. While all of our proposed alternative processes predict a correlation between monogamy and cooperation, and none are necessarily mutually exclusive to one another, there are clear differences between these different hypothetical evolutionary routes that lead to testable predictions (detailed in Table 2). Phylogenetic path analyses that incorporate additional factors, such as ecological and social selective pressures, pre-adapting traits, and sibling relatedness, will allow for identification of the most likely causal pathways and assessment of the strength of each variable's contribution to the evolution of cooperation.

Examinations of contemporary lineages could also provide insight into how these different processes act in ecological time. Investigating the strength and direction of selective pressures that influence both monogamy and cooperation, for example, could determine which factors are most important in maintaining both traits. In particular, the ways that sibling relatedness, environmental factors that influence both monogamy and cooperation (e.g. environmental harshness), and social selective pressures resulting from the establishment of ancestral monogamy interact to favor cooperation could be explored by examining the action of these selective pressures in contemporary lineages. For additional questions regarding the correlation between monogamy and cooperation, both in evolutionary and ecological time, see Outstanding Questions.

\section{Concluding remarks}


We have identified several important evolutionary and ecological processes that could contribute to the correlated evolution of monogamy and cooperation. We argue that monogamy influences cooperation in numerous ways, from increasing sibling relatedness, to creating or covarying with relevant selective pressures, to providing the basis for relevant standing variation for social traits. The main point we emphasize here is one that has been made many times before: that complex traits are not isolated variables that can be adjusted independently of one another, but rather represent highly interconnected components of a larger system composed of both the organism and its environment [64,65]. These sorts of holistic, systems-level approaches now characterize several other behavioral fields, including the study of parental decisions and mating decisions [11], as well as the study of suites of correlated behaviors, or behavioral syndromes [65]. We thus call for a similar paradigm shift towards recognizing the interdependence between mating systems and social systems, not only to better understand the correlated evolution of monogamy and cooperation, but also to stimulate the development of novel research avenues and insight into age-old questions about cooperative evolution.

\section{Acknowledgements}

We would like to thank Charles Fox, Phil Crowley, Catherine Linnen, Luc Dunoyer, Dustin Rubenstein, and an anonymous reviewer for helpful comments on this manuscript. J.R.D. was supported by a U.S. National Science Foundation Graduate Research Fellowship and the University of Kentucky, and D.F.W. by a regular grant (IOS1257718) from the U.S. National Science Foundation and the University of Kentucky. 


\section{BOX 1: The similarities between helpers and parents}

The similarities between the selective factors shaping monogamy and cooperation can be demonstrated using classic theory. A useful starting point is a simple modification [66] of Hamilton's Rule:

\section{(1) $r_{x} b-r_{y} c>0$}

where $b$ is the benefit of helping, measured as the increase in lifetime reproductive success for the receiver of help, and $c$ is the cost of helping, measured as the reduction in lifetime reproductive success for the helper. The benefits are modified by the relatedness between the helper and the offspring of the recipient $\left(r_{x}\right)$, and the costs by the relatedness coefficient between the helper and its own offspring $\left(r_{y}\right)[66]$. When the relatedness-modified benefits

outweigh the costs, helping is favored. Thus helping tends to be favored when the value of care (b) is high and when the costs $(c)$ are reduced, such as when helpers have low mating or dispersal success.

Similar cost-benefit models have been developed for monogamy and parental care as well $[14,67,68]$. We focus on Queller's [68] model where $x$ represents the total population reproduction, $m$ and $f$ are the numbers of males and females, respectively, $c$ is a coefficient of lost opportunities to mate given care (so $c X / m$ is equivalent to the $c$ in Hamilton's rule above; the number of offspring expected to be missed when providing care), $b$ is the gain in offspring per individual providing care, and $p$ is the fraction of offspring in the brood related to the father. In this model, males and females are selected to provide care when:

(2) $p b>c x / m$ 


\section{(3) $b>c x / f$}

Parental care, like helping, is selected when the benefits (to the offspring's fitness, $b$ ) outweigh the costs (to the parent's fitness, $c x /(m$ or $f)$ ). Though Queller [68] speculated as to the precise mechanisms of the fitness costs parents could incur, these costs and benefits could easily be interpreted as changes to lifetime reproductive success, as in Hamilton's Rule. This eliminates the need to compare cost currencies between sexes and makes clear that selection for parental care depends substantially on both the benefits of providing care and the costs from lost mating opportunities or reduced future reproductive success, as in the helper equation. Note that the benefits to males in this model are modified by his paternity in the brood, indicating that relatedness between actor and recipient is as important for paternal care to be favored as it is for helping $[11,69]$. 


\section{BOX 2: Relatedness as a dynamic variable}

Relatedness between interacting individuals has been previously recognized as a dynamic, rather than static, variable in certain theoretical treatments, particular those modeling dispersal strategies [70-72]. Though describing the full complexity of these models is beyond the scope of this discussion, the main point we wish to highlight from these studies is the codependency that arises between relatedness and the costs and benefits of dispersal. Limited dispersal results in high local relatedness, which dictates the inclusive fitness costs and benefits of dispersing. When local relatedness within a patch is high, competition between relatives reduces a focal individual's inclusive fitness (for a full review of competition and local relatedness see [73]), thus promoting dispersal, which in turn affects spatial relatedness patterns. Though the focus here is on dispersal strategies, the dynamic relationship between relatedness and dispersal has implications for cooperative or altruistic behaviors as well. Specifically, high costs for dispersing reduce the costs of helping while simultaneously increasing local relatedness, creating empirical complications for assessing the relative importance of relatedness and cost and benefit terms in the evolution of cooperation.

The fecundity distribution in the population is another factor that influences local relatedness and could have consequences for other terms in Hamilton's Rule [74]. Here, increasing variance in fecundity could increase local relatedness if one or a few individuals have comparatively high fecundity, resulting in a deme of mostly related individuals [74]. The factors that cause variance in fecundity, and thus patchy local relatedness, might themselves have effects on the costs and benefits of helping. Beckermann et al. [75], for example, show that predation, if targeted towards family groups, would not only contribute to variance in fecundity between families but also increase the benefits of cooperative defense, favoring kin-based cooperation by both increasing local relatedness and increasing the benefits of help. This provides a particularly cogent example of the idea that Hamilton's Rule is a description of a dynamic system and thus requires a systems-level approach to analyze correctly. 


\section{FIGURES \& TABLES}

\section{Figure 1. Schematic of the alternative hypotheses for the correlation between monogamy}

and cooperation. Arrows indicate positive relationships. Gray boxes and black arrows (a) represent the classic view of the monogamy hypothesis, indicating a causal relationship between monogamy and cooperation through sibling relatedness. Green boxes and arrows (b) depict how common selective factors could favor monogamy and cooperation simultaneously. Red boxes and arrows (c) show how traits favored for pair cooperation and parental care could be co-opted for use in more complex social contexts. Blue boxes and arrows (d) depict how the evolution of monogamy influences the social environment such that cooperation is favored. Finally, purple boxes and arrows show (e) how cooperation could increase selective pressure for monogamy.

Figure 2. Environmental influences on both mating and social behavior. (a) As an environmental factor that favors offspring care increases (e. g. food scarcity, nest predation, etc.), the fitness benefits to parents or helpers of providing care increase, favoring different levels of cooperative care along a proposed spectrum from uniparental care to cooperative brood care. Examples of these behavior categories depicted from right to left include a cluster of mating water striders (J. Dillard), a spawning Coho salmon pair with jack present (Copyright Thomas C Kline, Jr, used with permission), a Laysan albatross pair with eggs (Patte David, U.S. Fish \& Wildlife Service), and a gray wolf pack (Yellowstone National Park Service). (b) As the benefits of care increase, lineages might transition to genetic monogamy, raising sibling relatedness to 0.5 . The transition to cooperation therefore occurs due to a simultaneous increase in the benefits of care and sibling relatedness, both driven by the same ecological factors. 
Table 1. Summary of the ecological selective factors expected to influence both cooperation and monogamy similarly.

Table 2 Testable predictions of alternative processes giving rise to the correlated evolution of monogamy and cooperation in comparative studies. 


\section{References}

1 Boomsma, J.J. (2007) Kin selection versus sexual selection: why the ends do not meet. Curr. Biol. 17, R673-83

2 Boomsma, J.J. (2009) Lifetime monogamy and the evolution of eusociality. Philos. Trans. R. Soc. Lond. B. Biol. Sci. 364, 3191-207

3 Hamilton, W.D. (1964) The genetical evolution of social behaviour. I. J. Theor. Biol. 7, 116

4 Hughes, W.O.H. et al. (2008) Ancestral monogamy shows kin selection is key to the evolution of eusociality. Science (80-. ). 320, 1213-6

5 Cornwallis, C.K. et al. (2010) Promiscuity and the evolutionary transition to complex societies. Nature $466,969-72$

6 Leggett, H.C. et al. (2012) Promiscuity and the evolution of cooperative breeding. Proc. R. Soc. B Biol. Sci. $279,1405-11$

7 Lukas, D. and Clutton-Brock, T. (2012) Cooperative breeding and monogamy in mammalian societies. Proc. R. Soc. B Biol. Sci. 279, 2151-6

8 Kramer, K.L. and Russell, A.F. (2014) Kin-selected cooperation without lifetime monogamy: human insights and animal implications. Trends Ecol. Evol. 29, 600-606

9 Lukas, D. and Clutton-Brock, T.H. (2013) The Evolution of Social Monogamy in Mammals. Science (80-. ). 341, 526-530

10 Cezilly, F. and Nager, R.G. (1995) Comparative evidence for a positive association between divorce and extra-pair paternity in birds. Proc. R. Soc. B Biol. Sci. 262, 7-12

11 Alonzo, S.H. (2010) Social and coevolutionary feedbacks between mating and parental investment. Trends Ecol. Evol. 25, 99-108

12 Emlen, S. and Oring, L. (1977) Ecology, sexual selection, and the evolution of mating systems. Science (80-. ). 197, 215-223

13 Kokko, H. and Jennions, M.D. (2008) Parental investment, sexual selection and sex 
ratios. J. Evol. Biol. 21, 919-48

14 Maynard Smith, J. (1977) Parental Investment: A Prospective Analaysis. Anim. Behav. $25,1-9$

15 Trivers, R. (1972) Parental investment and sexual selection. In Sexual Selection and the Descent of Man, 1871-1971 (Campbell, B., ed), pp. 136-179, Aldine

16 Wittenberger, J. and Tilson, R. (1980) The Evolution of Monogamy: Hypotheses and Evidence. Annu. Rev. Ecol. Syst. 11, 197-232

17 Ketterson, E.D. and Nolan, V. (1994) Male Parental Behavior in Birds. Annu. Rev. Ecol. Syst. 25, 601-628

18 Westneat, D. et al. (1990) The ecology and evolution of extrapair copulations in birds. Curr. Ornithol. 7, 331-369

19 Emlen, S. (1982) The evolution of helping. I. An ecological constraints model. Am. Nat. $119,29-39$

20 Koenig, W.D. and Dickinson, J.L., eds. (2004) Ecology and Evolution of Cooperative Breeding in Birds, Cambridge University Press.

21 Koenig, W. et al. (1992) The Evolution of Delayed Dispersal in Cooperative Breeders. Q. Rev. Biol. 67, 111-150

22 Komdeur, J. (2006) Variation in Individual Investment Strategies among Social Animals. Ethology 112, 729-747

23 Cockburn, A. (2006) Prevalence of different modes of parental care in birds. Proc. $R$. Soc. B Biol. Sci. $273,1375-1383$

24 Bowen, W. (1981) Variation in coyote social organization: the influence of prey size. Can. J. Zool. 59, 639-652

25 Caraco, T. and Wolf, L. (1975) Ecological Determinants of Group Sizes of Foraging Lions. Am. Nat. 109, 343-352

26 Creel, S. (1997) Cooperative hunting and group size: assumptions and currencies. Anim. 
Behav. 54, 1319-24

27 Macdonald, D. et al. (2004) Society. In The Biology and Conservation of Wild Canids (Macdonald, D. and Sillero-Zubiri, C., eds), Oxford University Press

28 Ketterson, E.D. and Nolan, V. (1999) Adaptation, Exaptation, and Constraint: A Hormonal Perspective. 154,

29 Møller, A.P. and Cuervo, J.J. (2000) The evolution of paternity and paternal care in birds. Behav. Ecol. 11, 472-485

30 Møller, a. P. and Birkhead, T.R. (1993) Certainty of paternity covaries with paternal care in birds. Behav. Ecol. Sociobiol. 33, 261-268

31 Matysioková, B. and Remeš, V. (2013) Faithful females receive more help: The extent of male parental care during incubation in relation to extra-pair paternity in songbirds. $J$. Evol. Biol. 26, 155-162

32 Bales, K.L. et al. (2004) Both oxytocin and vasopressin may influence alloparental behavior in male prairie voles. Horm. Behav. 45, 354-361

33 Carter, S. and Roberts, R. (1997) The psychobiological basis of cooperative breeding in rodents. In Cooperative Breeding in Mammals (Solomon, N. G. and French, J., eds), pp. 231-267, Cambridge University Press

34 Faulkes, C.G. et al. (2013) Plasticity and constraints on social evolution in African molerats: ultimate and proximate factors. Proc. R. Soc. B Biol. Sci. 369, 1-10

35 Schoech, S. et al. (2004) Endocrinology. In Ecology and Evolution of Cooperative Breeding in Birds (Koenig, W. and Dickinson, J., eds), pp. 128-141, Cambridge University Press

36 Bender, N. et al. (2008) The role of prolactin in the regulation of brood care in the cooperatively breeding fish Neolamprologus pulcher. J. Exp. Zool. Part A Ecol. Genet. Physiol. 309, 515-524

37 de Ruiter, a J. et al. (1986) The effect of prolactin on fanning behavior in the male three- 
spined stickleback, Gasterosteus aculeatus L. Gen. Comp. Endocrinol. 64, 273-83

38 Dunbar, R.I.M. (1998) The Social Brain Hypothesis. Evol. Anthropol. 6, 178-190

39 Shultz, S. and Dunbar, R. (2010) Social bonds in birds are associated with brain size and contingent on the correlated evolution of life-history and increased parental investment. Biol. J. Linn. Soc. 100, 111-123

40 Shultz, S. and Dunbar, R.I.. (2007) The evolution of the social brain: anthropoid primates contrast with other vertebrates. Proc. R. Soc. B Biol. Sci. 274, 2429-2436

41 West, R.J.D. (2014) The evolution of large brain size in birds is related to social, not genetic, monogamy. Biol. J. Linn. Soc. 111, 668-678

42 Burkart, J.M. et al. (2009) Cooperative breeding and human cognitive evolution. Evol. Anthropol. 18, 175-186

43 Beauchamp, G. and Fernández-Juricic, E. (2004) Is there a relationship between forebrain size and group size in birds? Evol. Ecol. Res. 6, 833-842

44 Iwaniuk, A.N. and Arnold, K.E. (2004) Is cooperative breeding associated with bigger brains? A comparative test in the Corvida (Passeriformes). Ethology 110, 203-220

45 Kolliker, M. et al. (2012) Parent-offspring co-adaptation. In The Evolution of Parental Care (Royle, N. et al., eds), pp. 285-299, Oxford University Press

46 Moore, A.A.J. et al. (1997) Interacting phenotypes and the evolutionary process I. Direct and indirect genetic effects of social interactions. Evolution (N. Y). 51, 1352-1362

47 Wolf, J.B. et al. (1998) Evolutionary consequences of indirect genetic effects. Trends Ecol. Evol. 13, 64-69

48 Arnold, K. and Owens, I. (1999) Cooperative breeding in birds: the role of ecology. Behav. Ecol. 10, 465-471

49 Hatchwell, B. and Komdeur, J. (2000) Ecological constraints, life history traits and the evolution of cooperative breeding. Anim. Behav. 59, 1079-1086

50 Godfray, H. Evolutionary-Theory of Parent-Offspring Conflict. , Nature, 376. (1995) , 133- 
51 Burley, N.T. and Johnson, K. (2002) The evolution of avian parental care. Philos. Trans. R. Soc. B Biol. Sci. 357, 241-50

52 Ligon, J. and Burt, D. (2004) Evolutionary origins. In Ecology and Evolution of Cooperative Breeding in Birds (Koenig, W. and Dickinson, J., eds), pp. 5-34, Cambridge University Press

53 Arnold, K. and Owens, I. (1998) Cooperative breeding in birds: a comparative test of the history hypothesis. Proc. R. Soc. B Biol. Sci. 265, 739-745

54 Baglione, V. et al. (2005) Does year-round territoriality rather than habitat saturation explain delayed natal dispersal and cooperative breeding in the carrion crow? J. Anim. Ecol. 74, 842-851

55 Kokko, H. and Ekman, J. (2002) Delayed dispersal as a route to breeding: territorial inheritance, safe havens, and ecological constraints. Am. Nat. 160, 468-84

56 Rowley, I. and Russell, E. (1990) Splendid fairy-wrens: demonstrating the importance of longevity. In Long-term Studies of Ecology and Behavior (Stacey, P. and Koenig, W., eds), pp. 1-30, Cambridge University Press

57 Gadagkar, R. (1985) Kin recognition in social insects and other animals-A review of recent findings and a consideration of their relevance for the theory of kin selection. Proc. Indian Acad. Sci. Anim. Sci. 94, 587-621

58 Griffin, A.S. and West, S. a (2003) Kin discrimination and the benefit of helping in cooperatively breeding vertebrates. Science (80-. ). 302, 634-636

59 Komdeur, J. et al. (2008) Kin-recognition mechanisms in cooperative breeding systems: ecological causes and behavioral consequences of variation. In Ecology of social evolution (J, K. and J, H., eds), pp. 175-193, Springer-Verlag Berlin Heidelberg

60 Welbergen, J. a and Quader, S. (2006) Mother guarding: how offspring may influence the extra-pair behaviour of their parents. Proc. R. Soc. B Biol. Sci. 273, 2363-8 
61 Hardenberg, A. Von and Gonzalez-voyer, A. (2012) Dissentangling Evolutionary CauseEffect Relationships With Phylogenetic Confirmatory Path Analysis. Evolution (N. Y). 67, 378-387

62 Kruger, O. et al. (2014) Disentangling the contribution of sexual selection and ecology to the evolution of size dimorphism in pinnipeds. Evolution (N. Y). 68, 1485-1496

63 Swanson, E.M. and Dantzer, B. (2014) Insulin-like growth factor-1 is associated with lifehistory variation across Mammalia. Proc. R. Soc. B Biol. Sci. 281, 20132458

64 Gould, S.J. and Lewontin, R.C. (1979) The Spandrels of San Marco and the Panglossian Paradigm: A Critique of the Adaptationist Programme. Proc. R. Soc. B Biol. Sci. 205, $581-598$

65 Sih, A. et al. (2004) Behavioral syndromes: an ecological and evolutionary overview. Trends Ecol. Evol. 19, 372-378

66 West-Eberhard, M.J. (1975) The Evolution of Social Behavior by Kin Selection. Q. Rev. Biol. 50, 1-33

67 Fromhage, L. et al. (2007) Stability and value of male care for offspring: is it worth only half the trouble? Biol. Lett. 3, 234-236

68 Queller, D.C. (1997) Why Do Females Care More Than Males? Proc. R. Soc. B Biol. Sci. 264, 1555-1557

69 Westneat, D.F. and Sherman, P.W. (1993) Parentage and the evolution of parental behavior. Behav. Ecol. 4, 66-77

70 Gandon, S. and Roussett, F. (1999) Evolution of stepping-stone dispersal rates. Proc. $R$. Soc. B Biol. Sci. 266, 2507-2513

71 Gandon, S. (1999) Kin competition, the cost of inbreeding and the evolution of dispersal. J. Theor. Biol. 200, 345-364

72 Taylor, P.D. (1988) An inclusive fitness model for dispersal of offspring. J. Theor. Biol. 130, 363-378 
73 West, S. a et al. (2002) Cooperation and competition between relatives. Science (80-. ). 296, 72-5

74 Lehmann, L. and Balloux, F. (2007) Natural Selection on Fecundity Variance in Subdivided Populations: Kin Selection Meets Bet Hedging. Genetics 176, 361-377

75 Beckerman, A.P. et al. (2011) Predation and kin-structured populations: an empirical perspective on the evolution of cooperation. Behav. Ecol. 22, 1294-1303

76 Freed, L. (1987) The Long-Term Pair Bond of Tropical House Wrens: Advantage or Constraint? Am. Nat. 130, 507-525

77 Brown, J. (1987) Helping and communal breeding in birds: ecology and evolution, Princeton University Press.

78 Gill, S. a. and Stutchbury, B.J.M. (2006) Long-term mate and territory fidelity in neotropical buff-breasted wrens (Thryothorus leucotis). Behav. Ecol. Sociobiol. 61, 245253

79 Marzluff, J.M. and Balda, R.P. (1988) The advantages of, and constraints forcing, mate fidelity in pinyon jays. Auk 105, 286-295

80 Koenig, W. and Pitelka, F. (1981) Ecological factors and kin selection in the evolution of cooperative breeding in birds. In Natural Selection and Social Behavior: Recent Research and New Theory (Alexander, R. and Tinkle, W., eds), pp. 261-280, Chiron Press

81 Wilson, E. (1975) Sociobiology: The New Synthesis, 25th Anniv.Belknap Press.

82 Gamero, A. and Kappeler, P.M. (2015) Always together : mate guarding or predator avoidance as determinants of group cohesion in white-breasted mesites? J. Avian Biol. $46,378-384$

83 Mainwaring, M.C. and Griffith, S.C. (2013) Looking after your partner: sentinel behaviour in a socially monogamous bird. PeerJ 1 , e83

84 Norén, K. et al. (2012) From monogamy to complexity: social organization of arctic foxes (Vulpes lagopus) in contrasting ecosystems. Can. J. Zool. 90, 1102-1116 
85 Sorato, E. et al. (2012) Effects of predation risk on foraging behaviour and group size: adaptations in a social cooperative species. Anim. Behav. 84, 823-834

86 Riehl, C. (2011) Living with strangers: direct benefits favour non-kin cooperation in a communally nesting bird. Proc. R. Soc. B Biol. Sci. 278, 1728-1735

87 Heg, D. et al. (2004) Predation risk is an ecological constraint for helper dispersal in a cooperatively breeding cichlid. Proc. Biol. Sci. 271, 2367-2374

88 Alexander, R. (1974) The Evolution of Social Behavior. Annu. Rev. Ecol. Syst. 5, 325383

89 Rubenstein, D. (2011) Spatiotemporal environmental variation, risk aversion, and the evolution of cooperative breeding as a bet-hedging strategy. Proc. Natl. Acad. Sci. 108, $10816-10822$

90 Rubenstein, D.R. and Lovette, I.J. (2007) Temporal environmental variability drives the evolution of cooperative breeding in birds. Curr. Biol. 17, 1414-9

91 Dunn, P. and Hannon, S. (1992) Effects of Food Abundance and Male Parental Care on Reproductive Success and Monogamy in Tree Swallows. Auk 109, 488-499

92 Whittingham, L.A. and Robertson, R.J. (1994) Food Availability, Parental Care and Male Mating Success in Red Winged Blackbirds (Agelaius Phoeniceus). J. Anim. Ecol. 63, $139-150$

93 Heinsohn, R. (1992) Cooperative enhancement of reproductive success in white-winged choughs. Evol. Ecol. 6, 97-114

94 Faulkes, C. et al. (1997) Ecological constraints drive social evolution in the African molerats. Proc. R. Soc. B Biol. Sci. 264, 1619-1627

95 Emlen, S.T. and Wrege, P.H. (1991) Breeding Biology of White-Fronted Bee-Eaters at Nakuru: The Influence of Helpers on Breeder Fitness. J. Anim. Ecol. 60, 309-326

96 Beehler, B. (1985) Adaptive significane of monogamy in the trumpet manucode, Manucodia keraudrenii (Aves: Paradisaeidae). Ornithol. Monogr. 37, 83-99 
97 Choe, J. and Crespi, B., eds. (1997) The evolution of social behaviour in insects and arachnids, Cambridge University Press.

98 Stacey, P.B. and Koenig, W.D., eds. (1990) Cooperative Breeding in Birds: Long Term studies of ecology and behavior, Cambridge University Press. 


\begin{tabular}{|l|l|l|l|}
\hline Ecological Factor & \multicolumn{1}{|c|}{$\begin{array}{c}\text { Influence on } \\
\text { Monogamy }\end{array}$} & \multicolumn{1}{|l|}{ Influence on Cooperation } & References \\
\hline Limited nest sites & $\begin{array}{l}\text { Favors joint territory } \\
\text { defense and limits } \\
\text { alternate breeding } \\
\text { opportunities, favoring } \\
\text { monogamy }\end{array}$ & $\begin{array}{l}\text { Favors delayed dispersal by } \\
\text { reducing reproductive } \\
\text { opportunities }\end{array}$ & [76-80] \\
\hline Predation & $\begin{array}{l}\text { Increases benefits of } \\
\text { defending offspring and } \\
\text { partner, and increases } \\
\text { risk associated with } \\
\text { seeking additional mates }\end{array}$ & $\begin{array}{l}\text { Increases indirect and direct } \\
\text { benefits of cooperative defense, } \\
\text { increases dispersal costs, and } \\
\text { reduces probability of } \\
\text { successfully breeding } \\
\text { independently }\end{array}$ & [81-88] \\
\hline $\begin{array}{l}\text { Environmental } \\
\text { Unpredictability }\end{array}$ & $\begin{array}{l}\text { Favors monogamy as an } \\
\text { insurance strategy, } \\
\text { where biparental care } \\
\text { pays off when conditions } \\
\text { are unfavorable }\end{array}$ & $\begin{array}{l}\text { Increases benefits of helping } \\
\text { and delaying dispersal in } \\
\text { unfavorable years ("buffering") }\end{array}$ & [89,90] \\
\hline $\begin{array}{l}\text { Limited resources I: } \\
\text { Scarce resources }\end{array}$ & $\begin{array}{l}\text { Increases benefits of } \\
\text { biparental care } \\
\text { (increased provisioning } \\
\text { rate) }\end{array}$ & $\begin{array}{l}\text { Increases indirect benefits of } \\
\text { cooperative care (increased } \\
\text { provisioning rate). }\end{array}$ & [19,91-95] \\
\hline $\begin{array}{l}\text { Limited resources II: } \\
\text { Poor quality resources } \\
\text { (e.g. foliage, wood) }\end{array}$ & $\begin{array}{l}\text { Increases benefits of } \\
\text { biparental care } \\
\text { (increased provisioning } \\
\text { rate, enhanced resource } \\
\text { processing) }\end{array}$ & $\begin{array}{l}\text { Increases indirect benefits of } \\
\text { cooperative care (increased } \\
\text { provisioning rate, enhanced } \\
\text { resource processing) }\end{array}$ & [96-98] \\
\hline $\begin{array}{l}\text { Limited resources III: } \\
\text { Difficult to obtain } \\
\text { resources (e.g. prey) }\end{array}$ & $\begin{array}{l}\text { Increases benefits of } \\
\text { cooperative hunting (in } \\
\text { pairs) and defense of } \\
\text { prey }\end{array}$ & $\begin{array}{l}\text { Increases indirect benefits of } \\
\text { cooperative hunting (in groups) } \\
\text { and prey defense }\end{array}$ & [24,26,81] \\
\hline
\end{tabular}




\begin{tabular}{|c|l|}
\hline Hypothesis & Predictions \\
$\begin{array}{c}\text { Monogamy } \\
\text { hypothesis (sibling } \\
\text { relatedness) }\end{array}$ & $\begin{array}{l}\text { Variation in sibling relatedness per se will affect transitions } \\
\text { to cooperation when potential confounding factors are } \\
\text { controlled. }\end{array}$ \\
\hline $\begin{array}{c}\text { Ecologically driven } \\
\text { covariance }\end{array}$ & $\begin{array}{l}\text { Ecological factors predicted to favor both monogamy and } \\
\text { cooperation, such as predator pressure, food limitation, } \\
\text { environmental harshness, etc., will affect transitions to } \\
\text { both monogamy and cooperation. Accounting for them will } \\
\text { reduce the correlation between monogamy and } \\
\text { cooperation. }\end{array}$ \\
$\begin{array}{c}\text { Phylogenetic } \\
\text { facilitation through } \\
\text { pre-adaptations }\end{array}$ & $\begin{array}{l}\text { Cooperation will be more common in lineages with } \\
\text { ancestral adaptations to social living and cooperation, } \\
\text { such as pair boding, parental behavior, and parental } \\
\text { cooperation, than in lineages that do not possess these } \\
\text { traits. }\end{array}$ \\
\hline $\begin{array}{c}\text { Evolving and co- } \\
\text { evolving selective } \\
\text { pressures I: } \\
\begin{array}{c}\text { Monogamy favors } \\
\text { cooperation }\end{array}\end{array}$ & $\begin{array}{l}\text { Changes to the social environment favorable to } \\
\text { cooperative breeding, such as joint-territory defense, } \\
\text { habitat saturation, or highly altricial young will explain } \\
\text { transitions to cooperation when levels of sibling } \\
\text { relatedness and ecological factors are controlled. }\end{array}$ \\
\hline $\begin{array}{c}\text { Evolving and co- } \\
\text { evolving selective } \\
\text { pressures II: } \\
\begin{array}{c}\text { Cooperation favors } \\
\text { monogamy }\end{array}\end{array}$ & $\begin{array}{l}\text { Transitions to genetic monogamy would be more common } \\
\text { in cooperative lineages. Genetic monogamy would also } \\
\text { occur more frequently when kin recognition is present } \\
\text { once other factors, such as low density, are controlled. }\end{array}$ \\
\hline
\end{tabular}


b.

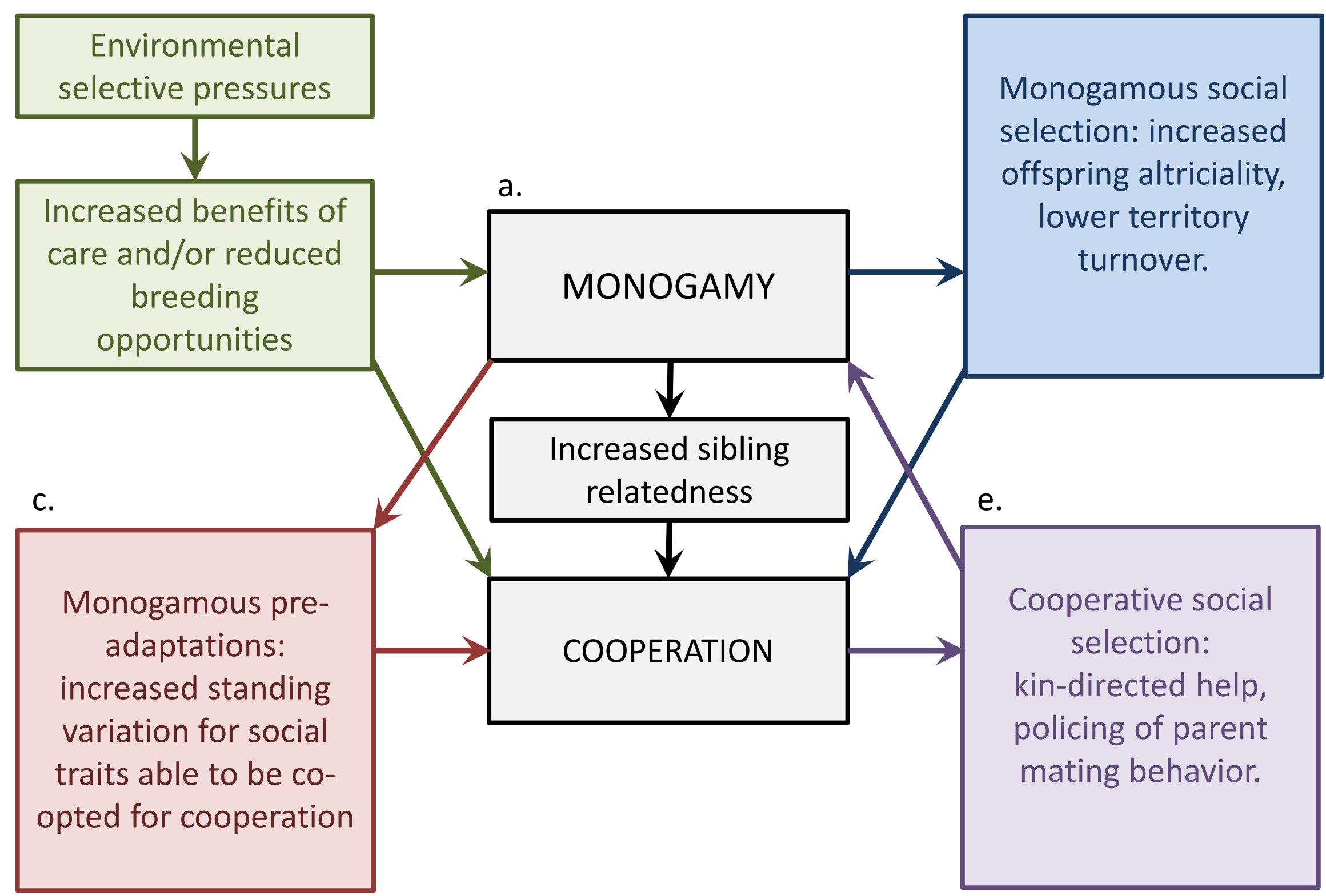




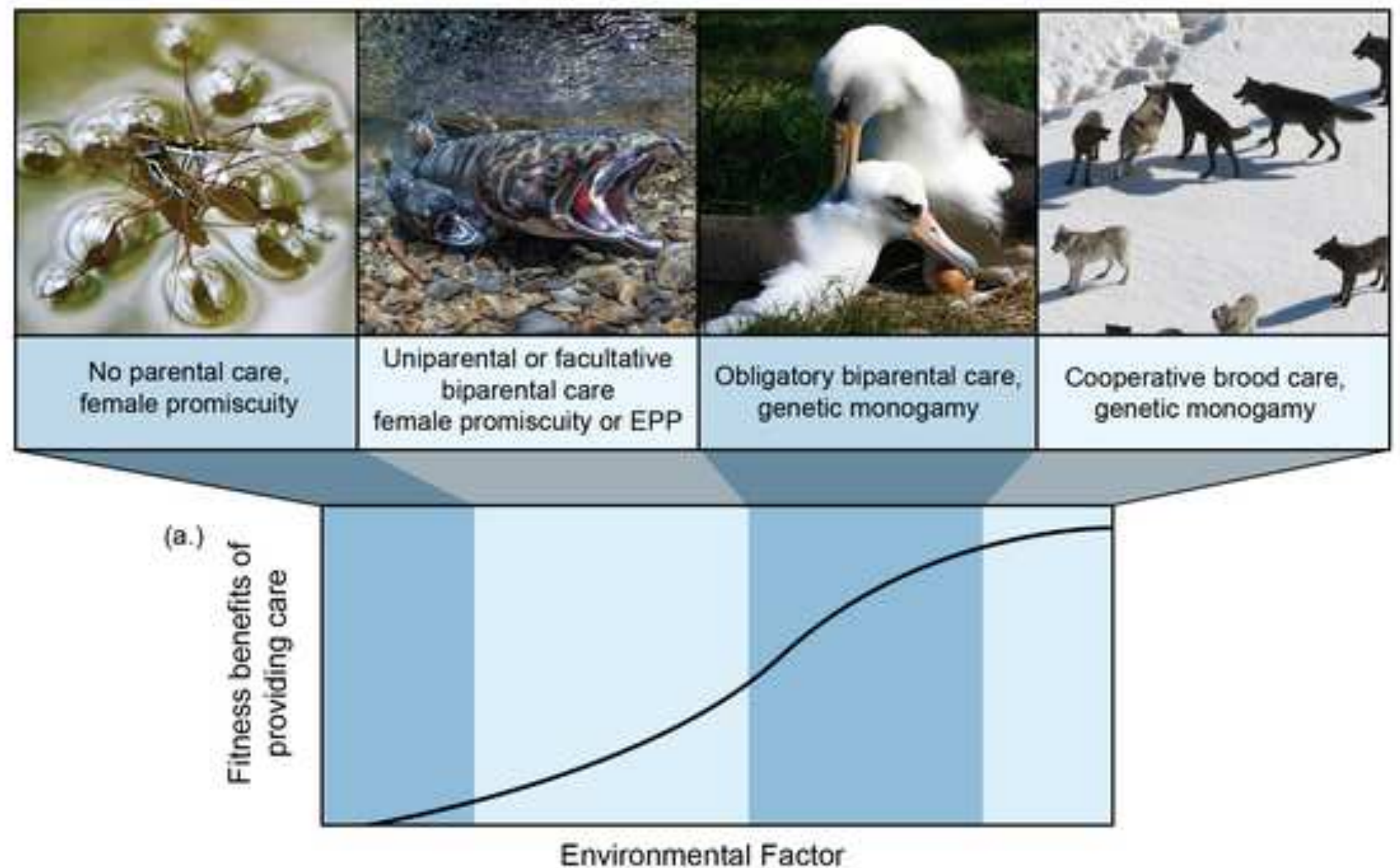

(b.)

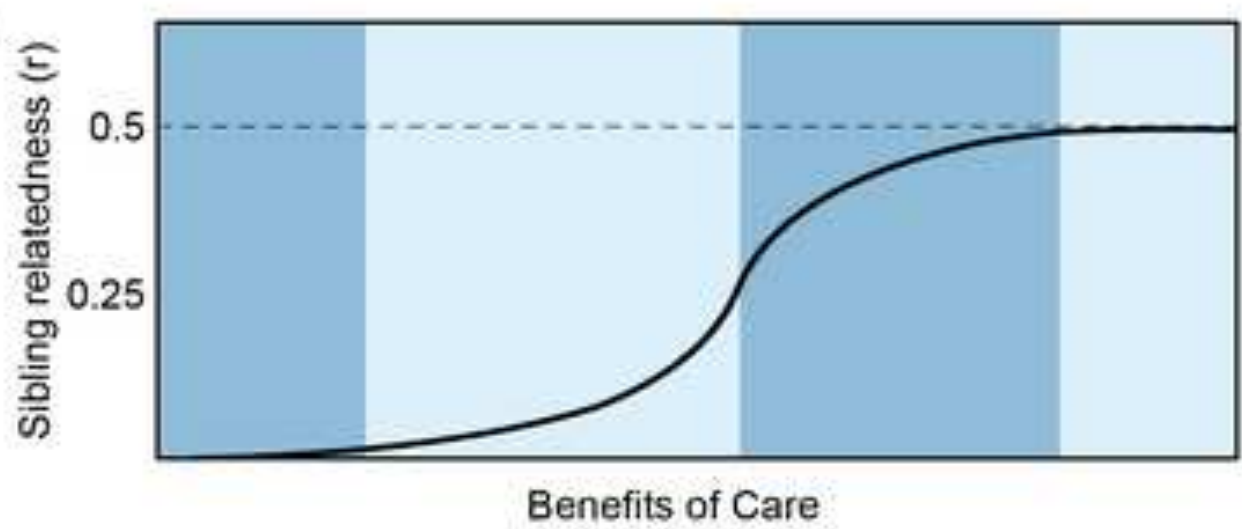


Figure 2 - Original Figure File

Click here to access/download

\section{Original Figure File \\ Figure2_revised.psd}

